\title{
¿EXPLOTADORES DE LA SALUD? UN ESTUDIO SOBRE MIRADAS MÉDICAS DESDE CÓRDOBA, ARGENTINA, EN TORNO A SABERES EMPÍRICOS VINCULADOS A LAS PRÁCTICAS DE CURAR (1930-1940)
}

\author{
Health exploiters? A study on medical views from Córdoba, Argentina, around \\ empirical knowledge linked to curing practices (1930-1940)
}

\author{
María Dolores Rivero* \\ https://orcid.org/0000-0002-0068-3281 \\ Adrián Carbonetti** \\ http://orcid.org/0000-0002-2093-2046
}

\section{Resumen}

Se colocarán bajo estudio discursos médicos provenientes de la medicina legal que giraron en torno a ciertas prácticas consideradas ajenas a la biomedicina "ética" durante las décadas de 1930 y 1940 , de manera específica, aquellas llevadas a cabo por curanderos y charlatanes. Nuestro análisis persigue el objeto de desenterrar las voces de dos figuras de relevancia vinculadas al campo "psi” y de la criminología en la provincia de Córdoba, que ocuparon espacios de prestigio y poder en el ámbito académico no sólo provincial, sino también nacional. Sus consideraciones sobre el curanderismo y el charlatanismo mostrarán, por un lado, un inquietante y continuo malestar de quienes formaban parte de las esferas del ámbito público. Convergentemente, el examen de esos entramados discursivos revelará que el "enemigo" no se encontraba sólo en las filas de quienes no poseían título universitario, sino que también era posible hallarlo dentro de los límites de la ciencia médica certificada. El corpus documental se halla constituido por escritos éditos e inéditos elaborados por los doctores Ariosto Licurzzi y Gregorio Bermann.

$$
<\text { Curanderos }><\text { Charlatanes }><\text { Saberes }><\text { Córdoba }>
$$

\begin{abstract}
In this paper, medical discourses from legal medicine that focused on certain practices considered to be bound to "ethical" biomedicine during 1930s and 1940s, specifically those carried out by "curanderos" and "charlatanes", will be studied. Our analysis aims to turn up the voices of two figures of relevance from the "psi" field and criminology in the province of Córdoba, who occuped spaces of prestige and power not only in the provincial academic field, but also in the national one. Their considerations about "curanderismo" and "charlatanismo" will show, on the one hand, a disquieting and continuous discomfort of those who were part of the spheres of the public domain. Convergently, the examination of these discursive frameworks will reveal that the "enemy" was not only among those who did not possess a university degree, but that it was also within the limits of certified medical science. The documentary corpus is constituted by edited and unpublished writings prepared by Drs. Ariosto Licurzzi and Gregorio Bermann.
\end{abstract}

$$
<\text { curanderos }><\text { charlatanes }><\text { knowledges }><\text { Córdoba }>
$$

Recibido: 01/10/2018//Aceptado: 21/12/2018

* Centro de Investigaciones y Estudios sobre Cultura y Sociedad (CIECS), Becaria doctoral del Consejo Nacional de Investigaciones Científicas y Técnicas (CONICET), Argentina, doloresriv@gmail.com

** Centro de Investigaciones y Estudios sobre Cultura y Sociedad (CIECS), Investigador Principal del Consejo Nacional de Investigaciones Científicas y Técnicas (CONICET), Argentina, acarbonetti2012@gmail.com 
Rivero y Carbonetti. ¿Explotadores de la salud? Un estudio sobre miradas médicas desde Córdoba, Argentina, en...

\section{Introducción}

En el campo de estudios históricos de la salud y la enfermedad, las variadas formas que vienen adoptando las prácticas del curar, y sus representaciones, revisten interés a la luz del rescate de entramados socio-culturales que se alejan de la clásica y restringida visión de la medicina como una disciplina cuyo progreso es inminente y continuo. Lejos quedaron las aproximaciones que de manera exclusiva ponderaban y enaltecían a las personalidades del campo científico-médico en Argentina, dando paso a nuevas perspectivas que colocan en foco de análisis, por ejemplo, a "las dimensiones sociodemográficas de una cierta enfermedad, las condiciones de vida, los instrumentos e instituciones del control médico y social, el rol del estado en la construcción de la infraestructura sanitaria, las condiciones de trabajo y sus efectos en la mortalidad", etc. (Armus, 2002, p. 45). De manera convergente, esta línea que se ha denominado "nueva historia sociocultural de la enfermedad" se ocupa, en variados aspectos, de los procesos de profesionalización y medicalización. El primero, de acuerdo con los señalamientos de González Leandri (1997; 1999) y Sarfatti Larson (1979), debe ser entendido a partir de dos lógicas indisolublemente vinculadas: la de la consolidación cognitiva (la configuración de los saberes científico -médicos) y la de la construcción de un monopolio en la práctica profesional médica del cuidado de la salud (exclusividad de los galenos en el ejercicio de las artes del curar). En lo relativo al proceso de medicalización, junto con Armus (2016), entendemos a este último como algo inacabado y en constante movimiento, cuyos compases e intensidad cambian a lo largo del tiempo y son desparejos en la trama social de una ciudad. De igual modo, no podemos dejar de destacar que los avatares que modelan las creencias y prácticas que saturan el mundo de la enfermedad y la salud en la modernidad urbana están signados por el mencionado proceso.

De acuerdo con nuestra perspectiva, la medicalización parcial e inconclusa en Córdoba —iniciada en el siglo XIX — puede ser leída a través de la aparición intermitente de un sinnúmero de personajes que disputaron el espacio, ocupado por la elite médica, grupo por excelencia adherente a una doctrina científica escasamente flexible y cuyas bases profesionales (pensadas en términos gremiales y de asociación) eran aún endebles en los albores del siglo XX. En el presente estudio nos interrogamos por discursos médicos — particularmente, aquellos provenientes de la medicina legal— que giraron en torno a ciertas prácticas, consideradas por los miembros de la élite galena como ajenas a la biomedicina "ética", durante las décadas de 1930 y 1940, de manera específica, aquellas llevadas a cabo por curanderos y charlatanes. Nuestro análisis persigue el objeto de desenterrar las voces de los doctores Ariosto Licurzi y Gregorio Bermann, figuras sobresalientes del campo "psi" y de la criminología en la provincia de Córdoba, que ocuparon espacios de prestigio y poder en el ámbito académico no sólo provincial, sino también nacional. Sus consideraciones sobre el curanderismo y el charlatanismo devienen fundamentales, pues mostrarán, por un lado, un inquietante y continuo malestar de quienes formaban parte de las esferas del ámbito público y que anhelaban detentar el monopolio cognitivo de las prácticas del curar. Convergentemente, el examen de 
esos entramados discursivos revelará que el "enemigo" no se encontraba sólo en las filas de quienes no poseían título universitario, sino que también era posible hallarlo dentro de los límites de la ciencia médica certificada. Este último rasgo imprimiría cierta particularidad al proceso de profesionalización en marcha, como también al de medicalización dentro de la provincia mediterránea.

De acuerdo con la bibliografía consultada, consideramos que las "prácticas curanderiles" y el "charlatanismo" (junto con sus detractores) no se posicionan de manera estelar en la historiografía contemporánea. Por el contrario, se trata de un campo de estudios notoriamente fértil; un mapeo por la producción latinoamericana de las últimas décadas da cuenta de ello. Sin embargo, no debemos perder de vista los aportes provenientes de Costa Rica, México, Colombia, Venezuela y Brasil ${ }^{1}$. Estas experiencias develan, como hemos mostrado en trabajos previos que, entre las postrimerías del siglo XIX y principios del XX, en América Latina la lucha de los médicos diplomados por posicionar su profesión frente a los practicantes irregulares tuvo características compartidas, mientras múltiples naciones se encontraban aun constituyéndose (Rivero y Vanadia, 2018, p.101). En efecto, estos procesos de consolidación académica y profesional solo se comprenden a la luz de sus interacciones con otras ofertas de cuidados que buscaban distanciarse y distinguirse de ellas, lo que entrañaría relaciones de tensión y rivalidad y un debate orientado a difundir el charlatanismo como enemigo de la salud pública, junto a la búsqueda de instrumentos de apoyo político y ciudadano para lograr un monopolio de la oferta terapéutica.

En Argentina, al igual que en el resto de Latinoamérica, no es dable observar una producción prolífica relativa a la temática referida. En nuestros límites nacionales detectamos apenas un conjunto de trabajos que abordan escenarios y figuras "curanderiles" en Buenos Aires (Armus, 2007 y 2016; Dahhur 2012, 2013 y 2018; Vallejo, 2015, 2016 y 2018), La Pampa (Di Liscia, 2002), Córdoba (Rivero y Vanadia, 2018; Rivero, Carbonetti y Rodríguez, 2017; Rodríguez, Aizenberg y Carbonetti 2018), Santa Fe (Allevi, Carbonetti, y Sedrán, 2018), Jujuy (Fleitas, 2014), Tucumán (Fernández y Parolo, 2008; Farberman, 2005). Una de las aproximaciones más complejas y extensivas, tal vez, sea la de Juan Pablo Bubello (2010), quien narra la historia de las peculiaridades fundamentales de los actores, objetos, representaciones y prácticas esotéricas en Argentina desde el período colonial hasta el siglo XX, dentro de las cuales incluye el curanderismo.

Los charlatanes, por su parte, han corrido la misma suerte -en términos historiográficos - que los individuos anteriormente reseñados. Posiblemente, la mayor y mejor revisión de este subconjunto provenga del análisis de Irina Podgorny (2012), pero desde una perspectiva marcadamente antropológica. Ahora bien, alejándonos de las vastas elaboraciones esbozadas en el seno de dicha disciplina, nuestra propuesta

1 Para el caso de Costa Rica véase Palmer (2002), y para el de México Módena (2002). Para indagar en el escenario colombiano véase Sowell (2002) junto con Márquez Valderrama, García y Delvalle (2012). La historiografía brasilera cuenta con los aportes de Salgado Pimenta (1997; 1998; 2003), Figueiredo (2002), de Sousa Soares $(1999 ; 2001)$ y Acosta Witter (2001; 2005). Véase Amodio (1997) para el caso de Venezuela. 
Rivero y Carbonetti. ¿Explotadores de la salud? Un estudio sobre miradas médicas desde Córdoba, Argentina, en...

intenta contribuir con una gran área de vacancia del conocimiento histórico, del universo aun escasamente explorado de las disputas en torno a los saberes y prácticas de curar en Córdoba, particularmente durante la primera mitad del siglo XX. Para ello, examinaremos los discursos de los doctores Ariosto Licurzi y Gregorio Bermann, centrándonos en lo que ambos galenos denominaron los "orígenes primitivos" del curanderismo, junto con sus mutaciones, derivaciones y manifestaciones en la provincia mediterránea. De manera convergente, nos adentraremos en la tónica del charlatanismo para ilustrar, a partir de un caso renombrado, los rasgos, alcances y riesgos que traería consigo el desarrollo de esta variante de las prácticas del curar empíricas, desde la óptica de los galenos. Realizaremos un análisis hermenéutico, que implica un ejercicio interpretativo intencional y contextual (Cárcamo Vásquez, 2005), de tres textos: (i) un libro escrito por Licurzi y publicado en el año 1937, (ii) un capítulo de un libro de autoría de Bermann, que vería la luz en 1941, y (iii) de un manuscrito, sin fechar, elaborado por este último autor. La primera obra se constituye como la fuente central de nuestro estudio, en la cual el autor realiza una sistematización y descripción densa del colectivo constituido por lo que él mismo denomina "los explotadores de la salud", mientras que los escritos de Bermann nos permiten completar - a partir de ejemplificaciones concretas y del estudio de un caso específico- el análisis de Licurzi.

\section{Ariosto Licurzi y Gregorio Bermann: sobre el curanderismo y sus orígenes}

Entre 1869 y 1914, la ciudad de Córdoba tuvo un crecimiento, en términos relativos, superior al de las ciudades de Rosario y Buenos Aires (Ansaldi, 1992). Las regiones restantes, si bien se constituyeron como puntos receptores de un flujo migratorio destacado, no tuvieron un incremento poblacional de la magnitud de la región pampeana. A pesar de que el mencionado crecimiento demográfico favorecía notoriamente a la economía agroexportadora del país, la elite criolla descubrió cómo la masa poblacional, que llegaba desde el otro lado del Atlántico, era portadora de un discurso de reforma radical opuesto a sus ideales. Así, la inmigración se traducía en la aparición de fenómenos políticos nunca antes vistos, como la formación de organizaciones con ideologías anarquistas y socialistafs, que comenzaron a tener un fuerte ascendiente sobre los trabajadores (Carbonetti, 2005). Asimismo, aquella afluencia de individuos hacia la Argentina traería aparejado un crecimiento urbano desmesurado, donde el desorden, el incremento de la pobreza, el hacinamiento, la delincuencia y la enfermedad comenzaban a adquirir un cariz especial para las autoridades. A partir de entonces comenzó a tomar forma la denominada "cuestión social" (Suriano, 2000), dentro de la cual se incluían también fenómenos de carácter laboral e ideológico, y sobre los cuales la élite gobernante advertía cierto grado de peligrosidad.

Para el caso de Córdoba del entre siglo, Moreyra y Dominguez (2012), señalan certeramente que:

(...) los desajustes y las exclusiones sociales que conformaron cuestión social- donde la problemática sanitaria era prioritaria - no ocuparon un lugar central en las agendas públicas y, por 
ende, no generaron una atención sistemática por parte de las diferentes instancias de Estado. El sistema asistencial estaba caracterizado por la pluralización de los actores y de los instrumentos de protección social y por la labilidad del límite entre la esfera pública y la privada (p. 167).

Concretamente, el modelo de asistencia social predominante en el ámbito nacional y en la sociedad cordobesa en particular, se hallaba signado por una relación de interdependencia entre las beneficencias de estructura esencialmente celular - y fuerte impronta religiosa - y el Estado. Este último vínculo implicaba que los funcionarios públicos confiaban en una pléyade de instituciones filantrópicas para los servicios sociales, sin un esquema planificador, y que aquellos organismos dependían del Estado para su funcionamiento legal y económico. El conjunto asistencial respondía, de este modo, a un modelo pluralista no proyectado con un fuerte predominio de la asistencia benéfica privada y una escasa participación del Estado como ente planificador, regulador y financiador (Moreyra y Domínguez, 2012).

Tal y como expresa Carbonetti (2005), en los albores la década de 1920 el concierto de salud pública cordobés comenzó a mutar, observándose en las estadísticas una fuerte disminución en la mortalidad provocada por enfermedades epidémicas. Por su parte, si bien las dolencias infectocontagiosas — junto con la mortalidad infantil—2 también mostraban rasgos de declinación, en este decenio se registró "un recrudecimiento del temor a la sífilis y la tuberculosis en la medicina estatal, percibidas como elementos debilitantes de la "raza Argentina", generando en el Estado nuevas prioridades en materia de salud" (Carbonetti, 2005, p. 112). A partir de entonces, hacia 1930, fue plausible observar un rol más activo de los gobiernos provincial y municipal en lo concerniente a la salud pública. En efecto, se produjo un viraje en la actitud prescindente del Estado respecto a las demandas de la población vinculadas a esta arista y se forjaron incipientes aumentos en los hospitales dependientes del mismo. Este proceso, además, se manifestó en el incremento de los espacios de consulta médica y en las tareas ligadas a la medicina preventiva. Sin embargo, siendo uno de los enclaves urbanos más populosos - 300.000 habitantes-, Córdoba disponía de apenas seis hospitales generales para cubrir la demanda de la ciudad y la proveniente del interior provincial: el Hospital Universitario, el Hospital de Niños de la Sociedad de Beneficencia, el Español y el Italiano de las sociedades de beneficencia de sendas colectividades y el Hospital San Roque bajo el patronato del gobierno provincial (Ortiz Bergia, 2015). En consecuencia, ese esquema público se manifestaba como un deficiente tendido de dispositivos, que no se adecuaban a la dispersión geográfica ni al volumen de su población. Los médicos distaban de lograr "el monopolio del saber y de las prácticas médicas" y debían competir con otras estrategias de acceso a la salud como los curanderos (Moreyra, 2009, pp.72-73, 129-130). Es precisamente en la década del 30' que el Dr. Ariosto Licurzi ${ }^{3}$, especialista en medicina

\footnotetext{
2 Para mayor información, véase Carbonetti (2003).

3 Nació en Buenos Aires en 1890 y se graduó en la Universidad de Córdoba en 1921. Asistió a cursos de especialización en Roma; adscribiéndose a la cátedra de medicina legal y toxicología de la Universidad
} 
Rivero y Carbonetti. ¿Explotadores de la salud? Un estudio sobre miradas médicas desde Córdoba, Argentina, en...

legal y toxicología de la Universidad de Córdoba, escribío su obra "Los explotadores de la Salud. Curanderos y Charlatanes. Estudio médico- legal y criminológico". La riqueza de dicho trabajo lo constituye como la fuente fundamental de nuestro estudio, pues grafica de manera acabada una amplia presencia de personajes variopintos, que desempeñaron sus actividades por fuera de los márgenes de la biomedicina en Córdoba, así como la percepción del mencionado galeno acerca de ellos.

La organización del libro de Licurzi nos remite, indefectiblemente, a un ansia clasificatoria propia del positivismo decimonónico. El documento se encuentra estructurado a partir de las tres formas en que el médico concebía que era "explotada la salud". La primera era el curanderismo verdadero, dentro del cual incluía a los "pillos y pseudoiluminados" y a todos sus actos curanderiles: "con palabras, con agua y hierbas, con remedios varios; llámense adivinos o brujos, tatadioses o ascetas, mesmeristas, espiritistas, compositores de huesos y psicometras"4. El segundo grupo, de acuerdo a su visión, se hallaba compuesto por dos variedades de explotadores: "la primera (...) es el curanderismo de frontera, porque lo realizan los farmacéuticos, estudiantes de medicina, parteras, etc, que viven en las fronteras de la medicina (...) la segunda es el curanderismo impersonal ${ }^{5}$, que se realiza indirectamente a través de una publicidad permitida, tasada y pagada"6. Finalmente, en un tercer grupo, Licurzi colocaba a los charlatanes, entre los cuales se encontraban quienes formaban parte del pleno campo de la medicina: médicos que harían propagandas excesivas, inescrupulosas y que articularían procedimientos de cura no reconocidos por la comunidad científica toda.

Ahora bien, para ingresar en el desarrollo de esta taxonomía, Licurzi incluía una explicación acerca de la génesis de estas prácticas curanderiles, directamente imbricada, según su entender, a la "ignorancia y superchería". Tal vez, le resultase necesaria aquella reconstrucción, puesto que, desde su óptica, el mundo moderno del positivismo científico era absolutamente incompatible con aquel "estado (...) derivado de la ignorancia y el temor". Su discurso, teñido de una tónica racionalista, exaltaba las "adquisiciones intelectivas" propias de la modernidad. Ese sujeto social ("mentalmente evolucionado") que transitaba el "mundo civilizado" no había conseguido aún liberarse de los miedos y las angustias ancestrales, como consecuencia de un estadio psíquico individual y colectivo anclado en la "inquietud y la sugestionabilidadad" . La persistencia de ambas características a lo largo de la historia tornaría fácil el retorno a lo que Licurzi denominaba "la infancia psíquica". Lo que particularmente el galeno identificaba como base del curanderismo primitivo era la sugestión, animada por el primer gran instrumento utilizado por "los más vivos": la palabra. Ésta era la herramienta, por excelencia, destinada a la expulsión de las dolencias "generadas por espíritus malignos

de Córdoba. Fue luego profesor suplente y, desde 1942, titular de esa materia. Estaba vinculado a los centros criminológicos del país y del extranjero (Ferrari, 2011).

4 Licurzi, 1937, p. 7.

5 La cursiva es del autor.

6 Licurzi, 1937, pp. 7-8.

7 Licurzi, 1937, pp. 3-4. 
o genios del mal penetrados en el organismo". En una fase ulterior, la enfermedad sería obra de un enemigo humano poseedor de un poder sobrenatural, cuyos sortilegios podrían ser revertidos mediante las habilidades de hechiceros y sacerdotes. Aquellas entidades serían parte de lo que Gregorio Bermann — reconocido nada más y nada menos que como el introductor del psicoanálisis en Córdoba, participante de la Reforma Universitaria de 1918, predecesor de Licurzi en la cátedra de Toxicomanía y Médicina Legal- denominaba “el pensamiento mágico", mediante el cual se establecería una red de relaciones particulares, un cuadro sintético del mundo que afectaría de manera directa los sentimientos y las pasiones de los hombres primitivos ${ }^{9}$. De manera convergente, en la proyección de los impulsos psíquicos en el mundo “(...) el hombre crea el animismo faz-preliminar de las representaciones religiosas del cosmos, poblando al mundo exterior de fuerzas ó [sic] de demonios (...)"10 que serían los responsables últimos del deterioro de su salud. De esta manera, el animismo tendría un papel central en medicina ${ }^{11}$.

Va de suyo que aquel sólo sería, como señala el autor, un estadio inicial en la configuración de las concepciones acerca de la enfermedad y sus posibles sanaciones. Posteriormente, "fue necesario asociar a los gestos indescifrables y a las palabras arcanas algo material". Junto con Moreyra (2011, p. 124), consideramos que "la noción de cultura material no es sinónimo de objetos materiales, sino que, por el contrario, involucra las prácticas y representaciones sociales que surgen de la permanente convivencia e interacción entre el hombre y los objetos". En esta segunda fase del curanderismo universal planteada por Licurzi, el empleo del agua y los vegetales con fines terapéuticos sería clave. La elección de aquellos materiales no fue casual, según el autor, pues se trataría de símbolos por excelencia de la "naturaleza panteísta ${ }^{12 " 13}$. A partir de esta aprehensión del universo, el galeno aseveraba que fue tomando forma la figura del curandero naturista, al calor del desarrollo de: "dos fenómenos de fuerte acción psíquica subordinados uno al otro: objetivamente, la incomprensión de ciertos hechos; subjetivamente, la necesidad, la ventaja, diría, de deformarlos y rodear de valores muy diversos de los reales la personalidad del curandero ${ }^{14}$. Estos fenómenos fueron así dotando de condiciones extraordinarias y/o sobrenaturales, cada vez más extravagantes, a sujetos que terminaron adquiriendo reconocimiento y prestigio progresivamente en el entorno social, hasta llegar a un escenario de marcada complejidad, signado por múltiples prácticas y elementos de "trabajo". Todos ellos, de acuerdo a Licurzi,

8 Licurzi, 1937, p. 10

9 John Kretschener llamaría "formaciones psiquícas catatímicas" a estos contenidos psíquicos influenciados por factores afectivos. La psiquiatría actual reconoce la existencia de ilusiones catatímicas, que consisten en la participación de la emoción en el mecanismo de deformación de lo percibido (Gastó y Navarro, 2006).

10 Berman, s/d.

11 Estas reflexiones se encuentran contenidas en una carta escrita por el Dr. Bermann, perteneciente al archivo que lleva su nombre, ubicado en el Centro de Estudios Avanzados (Córdoba, Argentina), que no se halla fechada.

12 Arana Cañedo (2001), citando a John Toland (teólogo irlandés), explica que se trata de una forma de concebir el mundo en la cual no hay ningún ser divino distinto de la materia y de este mundo, y de la naturaleza misma, es decir, la totalidad de las cosas, es el único y más alto Dios.

13 Licurzi, 1937, p. 12.

${ }^{14}$ Licurzi, 1937, p. 13. 
Rivero y Carbonetti. ¿Explotadores de la salud? Un estudio sobre miradas médicas desde Córdoba, Argentina, en...

conformarían variadas modalidades de "delincuencia social" ${ }^{15}$. Aquel concepto, sin lugar a dudas, se hallaba imbricado a la idea, acuñada en el marco de la modernidad, de que "era necesario articular un orden social, un substrato normativo que superase a los individuos y se impusiese a ellos" (Huertas, 2012, p. 23). La ciencia se convertiría en una de las herramientas fundamentales para la normalización social, para la restitución de la "norma" moral de los "desviados"; empero, como permite constatar nuestro corpus documental, aquella tarea se tornaría ardua para la élite médica cordobesa. Como veremos a continuación, un variopinto conjunto de empíricos transgredía los principios de orden y progreso sistemáticamente.

\section{Algunas especificidades sobre "curanderismo verdadero" y sus representantes}

Sin ánimos de extendernos y adherirnos al ansia clasificatoria de Ariosto Licurzi, resulta ineludible para nuestro estudio la desagregación del complejo abanico de personalidades que conformaran lo que el autor denominase "curanderismo verdadero".

Una de las figuras asociadas a la bondad, a lo profético — desde la sabiduría popular-, fue la del tatadiós. Se trataba, en general, de personalidades cuya labor en apariencia desinteresada y humanitaria, mitigaría las penas de sus vecinos. Como contrapunto, el brujo poseía capacidades similares a la del tatadiós, pero sería buscado para "producir el mal", ayudado por "espíritus malignos y/o demoníacos" ${ }^{16}$ y a través de determinados objetos como los que se observan en las figuras 1 y 2 .

El siguiente subgrupo se encontraba compuesto, fundamentalmente, por espiritistas. Desde la óptica del autor, éstos estarían directamente asociados al complemento religioso. Como señala Vallejo (2015), las creencias y los rituales kardecianos ${ }^{17}$ fueron interpretados y explicados por los doctores de manera tal que:

(...) los médicos se alinearon claramente con los tribunos
del catolicismo. Desde bien temprano la Iglesia local decidió
presentar batalla contra el espiritismo. En lo que constituye
el primer tratado sobre magnetismo publicado en el país, la
obra escrita en 1872 por el presbítero Miguel Angel Mossi
contiene de alguna forma muchos de los preceptos con que los
católicos condenarán al espiritismo durante largas décadas ${ }^{18}$.
Mediante el establecimiento de una analogía entre espiritismo
y magnetismo, el autor efectuaba una condena moral de ambos
elementos, acusándolos de poseer una naturaleza diabólica,
(p.22).

${ }^{15}$ Licurzi, 1937, p.14.

${ }^{16}$ Licurzi, 1937, p. 17.

${ }^{17}$ Término que hace referencia a Allan Kardec, máximo exponente de la doctrina francesa originada a mediados del siglo XIX conocida como "espiritismo" (Vallejo, 2016).

${ }^{18}$ Para mayor información véase Mossi (1872). 
Figuras 1 y 2
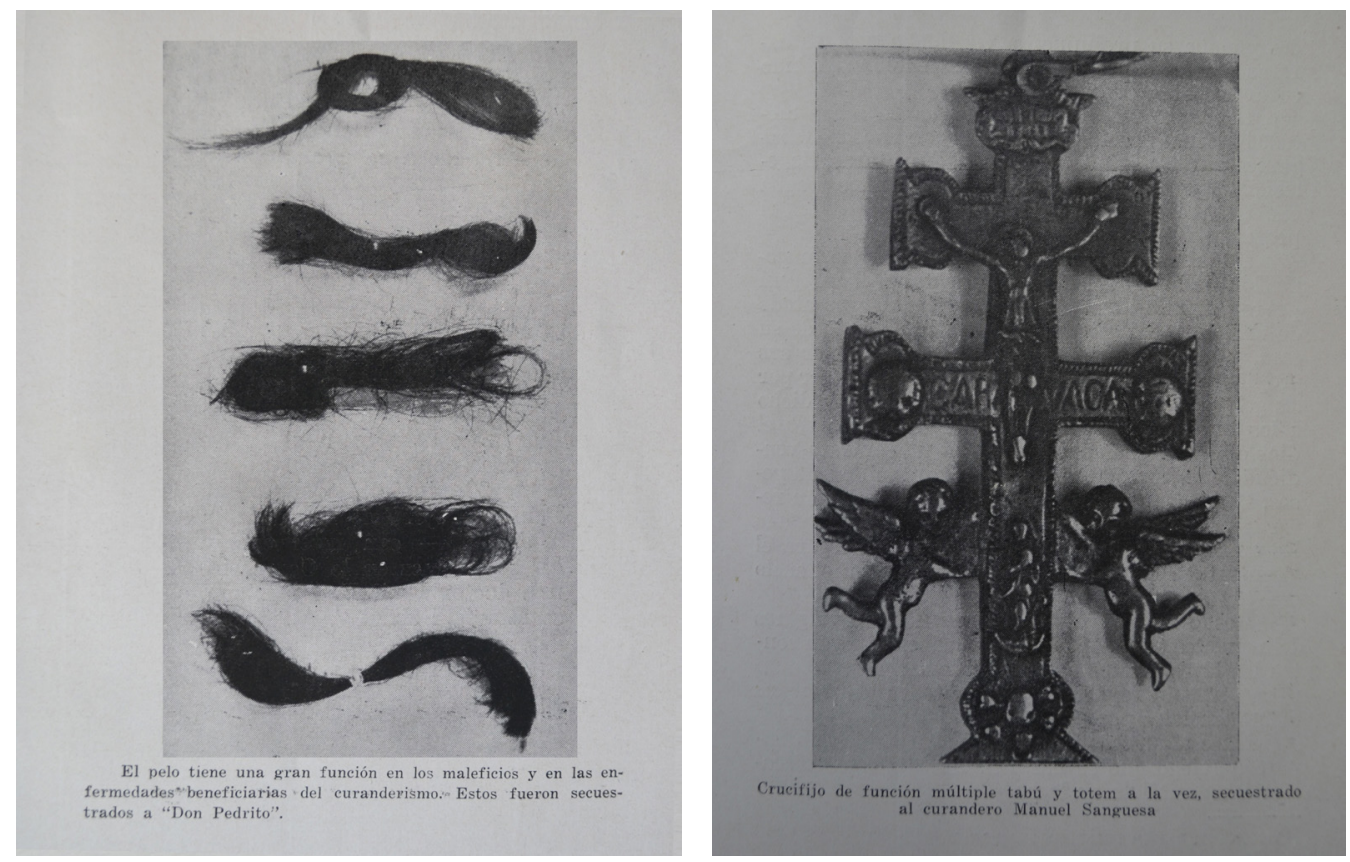

Los médicos se sumaron poco después a esa empresa. Para el caso de Córdoba, resulta insoslayable el estudio de Wilfrido Rodríguez de la Torre, Espiritismo y locura, publicado en 1889, en el cual es posible entrever la hipótesis de que la frecuentación de las ideas y prácticas espiritistas podía funcionar como factor etiológico de la alienación, como también la tesis de que la defensa del espiritismo sería en verdad la consecuencia o el síntoma de un desarreglo ya existente (Vallejo, 2016, p. 309). Sin embargo, esta suerte de asociación entre médicos y eclesiásticos no estaría libre de excepciones. En efecto, algunos pasajes de "Los explotadores de la salud..." permiten reconocer cierta condena de parte de Licurzi hacia las prácticas y rituales propios del catolicismo. De acuerdo a su visión, sacerdotes, monjes o miembros de instituciones religiosas llevaban a cabo ejercicios curanderiles -al estilo de los milagros de la virgen de Lourdes- que, frecuentemente, lograban considerable suceso. Aquel resultado devenía de la fama de la que gozaban estos empíricos: se trataba, mayoritariamente, de personajes ilustrados ${ }^{19}$. Podemos argüir que, en términos generales, esa sería una característica extendida a todo el grupo de espiritistas y, precisamente, determinaría la estirpe del público asistente a las "sesiones"; en algunas de ellas, incluso, "se evocarían espíritus de varios médicos difuntos (...) una especie de junta médica en pro de la salud del enfermo"20. Licurzi reconocía que estos escenarios se montaban habitualmente en entornos urbanos y que

\footnotetext{
${ }^{19}$ Licurzi, 1937, p.26.

${ }^{20}$ Licurzi, 1937, p.36.
} 
Rivero y Carbonetti. ¿Explotadores de la salud? Un estudio sobre miradas médicas desde Córdoba, Argentina, en...

quienes los transitaban eran aquellos de "clase elevada" ${ }^{21}$. Se trataba, pues, de actividades llevadas a cabo y consumidas por un segmento selecto de la población.

Ahora bien, no sorprende el hecho de que el galeno criminalista omitiese algunos detalles relativos a la formación intelectual de los empíricos mediums. Tan sólo en el caso de los clérigos reconocía que "tienen una mediana ilustración general como complemento a la teológica" ${ }^{22}$. Una revisión de antecedentes señala, no obstante, que muchos de los personajes que desarrollaban estas prácticas formaban parte del "campo científico". Ovidio Ribaudi, por ejemplo, famoso por su gran labor en el área de la ciencia y sus descubrimientos respecto a la química, participó asiduamente de actividades y experiencias variadas; el estudio intensivo del fluido magnético, la lectura del pensamiento y la exteriorización de la sensibilidad, todas ellas percibidas y examinadas como terapias alternativas durante el último cuarto del siglo XIX en Buenos Aires (Bianchi, 2012). Evidentemente, aquella acción de eludir el componente erudito de científicos que se volcaban por lo "paranormal", respondería a una suerte de negación u ocultamiento en el seno de la élite médica cordobesa. En efecto, resultaba prácticamente inimaginable que individuos formados en academias nacionales e internacionales optasen por acercarse a este mundo donde, aparentemente, no primaba la racionalidad.

Ciertas prácticas curanderiles mostrarían especificidad en cuanto al diagnóstico y tratamiento de determinadas partes del cuerpo. Licurzi identificaba, por ejemplo, la existencia de un curanderismo de carácter estético llevado a cabo por manicuros, pedicuros y masagistas [sic]. Se trataría, fundamentalmente, de sujetos que estarían "subordinados al arte médico y contarían con algunos privilegios y comodidades"23; entre ellos, la autorización legal — a partir del pago de una patente- $-\mathrm{y}$, por ende, la posibilidad de publicitar sus servicios en la prensa. No obstante, el problema en estos casos radicaba, según el galeno, en que esa habilitación terminaba por servir “(...) para realizar actos abiertamente inherentes a la medicina y cirugía" 24 . Ahora bien, un detalle no menor es la derivación que, en sendas oportunidades, realizaban los propios médicos hacia los practicantes de estos oficios. En ese caso, señalaba el galeno, terminaban por acrecentar las filas de pacientes de estos "contrabandistas de la salud" 25 .

Los componedores de huesos, por su parte, fueron reconocidos por Licurzi por sus destrezas y conocimientos adquiridos a partir de una extensa práctica. Este punto resulta clave para nuestro estudio, pues el médico criticaba y tensionaba la formación y el devenir de la profesión. De acuerdo a su experiencia, las habilidades de estos "ostéopatas empíricos" faltaban a muchos médicos que no habrían podido adquirirlas en un sistema de enseñanza excluyente, que les permitió a unos pocos realizar la observación y experimentación necesaria en clínicas y hospitales. Podemos suponer, entonces, que casi veinte años después el movimiento reformista que tuviese cuna en la provincia mediterránea, la democratización y horizontalidad de la enseñanza (Tunnerman, 2008)

\footnotetext{
${ }^{21}$ Licurzi, 1937, p.33.

${ }^{22}$ Licurzi, 1937, p. 26.

${ }^{23}$ Licurzi, 1937, p. 40.

${ }^{24}$ Licurzi, 1937, p. 41.

${ }^{25}$ Licurzi, 1937, p. 43.
} 
eran asuntos pendientes, al menos en la Facultad de Ciencias Médicas. Sin embargo, localizados tanto en entornos rurales como en las urbes, estos personajes "criollos" fueron frecuentados, observaba Licurzi, con la finalidad de "economizar". En otros términos, la visita al médico diplomado no era eludida por la experticia del componedor, sino por las facilidades monetarias que éste ofrecía.

Otros representantes del "curanderismo verdadero" fueron los iridiólogos; estos realizarían el diagnóstico de todo tipo de enfermedades a través de iris, práctica que habría "creado especialistas hasta en los médicos"26. A propósito de un caso particular (el de un "pseudo-indú [sic]- alemán, que en realidad era italiano), Licurzi aseguraba que "(...) los diagnósticos que hace son genéricamente equivocados, sin otra base que los datos que el paciente le facilita. Sus tratamientos no varían substancialmente (...)". Empero, lo cierto es que "iridiólogo" Cauca (ver figura 3) atraía pacientes de todas las esferas sociales, incluso "hasta la señora de un hombre de gobierno"27.

Figura 3

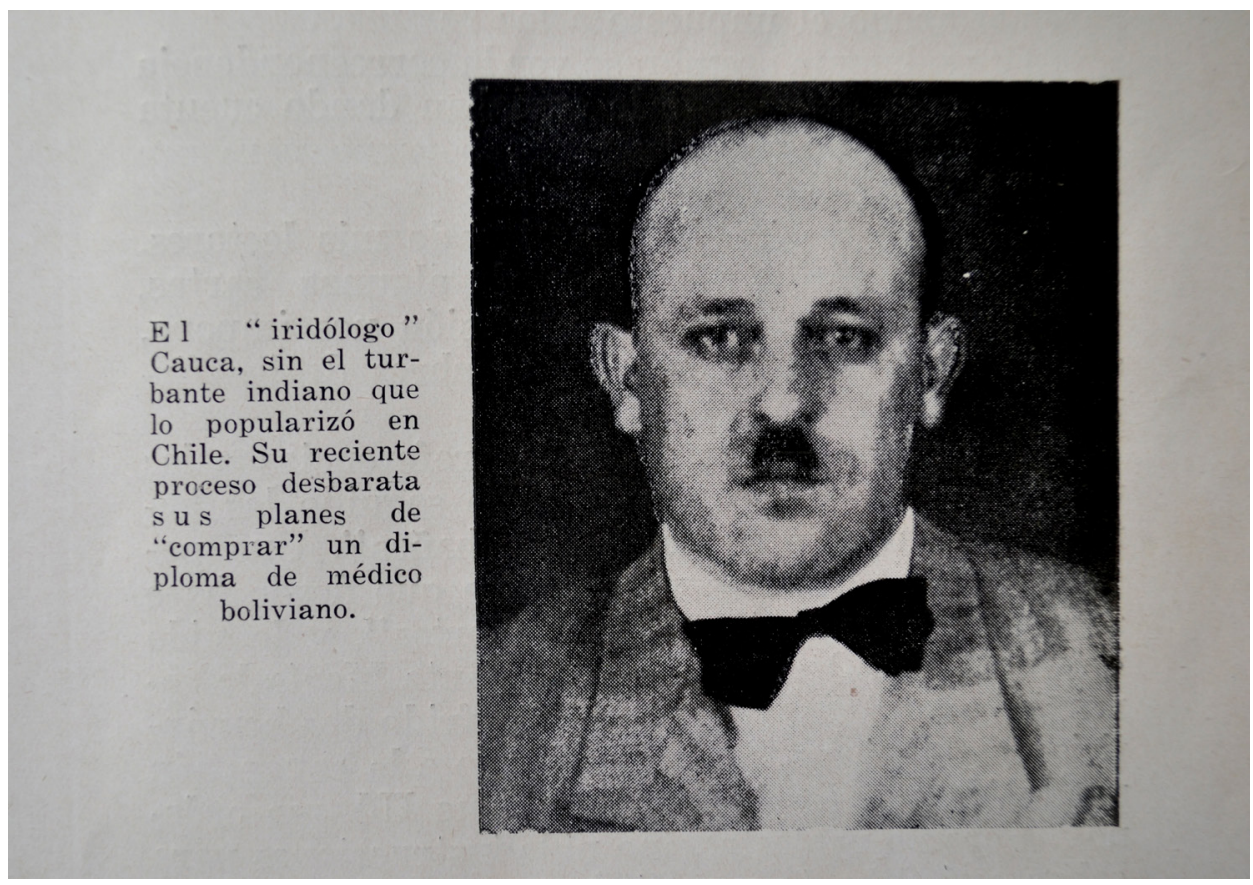

La psiquis sería una entidad abordada por psicometras y curanderos psiquiátricos. Los primeros eran descriptos por Licurzi como "individuos que en contacto con un objeto perteneciente a una persona presente o lejana, viva o muerta, saben dar datos personales, indicaciones e intuir cosas desconocidas a veces por los

\footnotetext{
${ }^{26}$ Licurzi, 1937, p. 47.

27 Licurzi, 1937, p. 48.
} 
Rivero y Carbonetti. ¿Explotadores de la salud? Un estudio sobre miradas médicas desde Córdoba, Argentina, en...

mismos interrogantes, y que a veces resultan verdaderas"28. Licurzi identificaba en estos "explotadores" la capacidad de ejercer influencia psicológica en "personas de labilidad temperamental" creando "estados de conciencia de la enfermedad que no existía"29. Así llegaban, incluso, a ser visitados por médicos, hecho que les confería mayor prestigio. Los curanderos psiquiatras, por su parte, eran consultados ante situaciones de confusión entre enfermedades psiquiátricas y brujería o maleficios. En efecto, "casi siempre el curanderismo que se refiere a enfermedades mentales y nerviosas, va

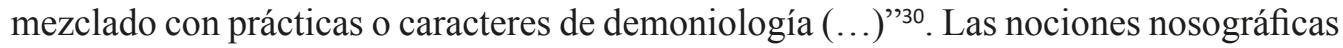
y conocimientos de psiquatría, según el galeno, no eran de fácil interpretación y adquisición popular; por tanto, no se habría desarrollado una suerte especialización. Ante este escenario de desconocimiento, lo que primaba eran “(...) ritos extravagantes, raros, brutales, castigos, quemaduras, flagelaciones, prolongada privación de alimentos y agua, etc [...] En otras ocasiones, empero, recurrían hasta al léxico psiquiátrico y hablaban de sugestión, autosugestión, etc"31.

\section{Entre las fronteras y lo impersonal}

Casi en las puertas de la disciplina médica se desarrollaría otro tipo de prácticas curanderiles, de acuerdo a la percepción de Licurzi. Se trataba de aquellas que eran ejercidas y extendidas por individuos cercanos a la medicina diplomada, posicionados en un lugar fronterizo. Naturalmente, desde la óptica del galeno, esto implicaba un alto grado de gravedad, pues a partir de determinadas enseñanzas básicas impartidas por médicos especializados, o de la simple observación, estos personajes terminarían por colmar el campo de las artes de curar. Belmartino (2005) señala que algunos de estos individuos eran auxiliares reconocidos y llevaban a cabo actividades legitimadas, que iban incrementando sus labores a medida que los profesionales aumentaban su público y las prácticas se tornaban más complejas. Durante los años 30', precisamente, los médicos cambiarían de actitud frente a estos ayudantes, "cuando la disminución de la clientela en sus consultorios o la dificultad para iniciar una práctica independiente se hicieron efectivas o bien se presentaron como una amenaza potencial para el futuro" (Belmartino, 2005, p. 88). Así, por ejemplo, muchos enfermeros (siempre identificados con el género masculino en los escritos del médico ${ }^{32}$ ) eran considerados "personas sin instrucción científica ni común, por lo general, sin cultura alguna". Ahora bien, pese a esa suerte de total carencia de inteligencia o sentido común, Licurzi reconocía que los enfermeros

\footnotetext{
${ }^{28}$ Licurzi, 1937, p. 52.

${ }^{29}$ Licurzi, 1937, p. 55.

${ }^{30}$ Licurzi, 1937, p. 55.

${ }^{31}$ Licurzi, 1937, pp.58-60.

${ }^{32}$ Esto llama nuestra atención, pues como ha señalado recientemente Martin (2015), una vez transcurrida la primera década del siglo XX, más del $70 \%$ de quienes se dedicaban a la enfermería en la ciudad de Buenos Aires -por ejemplo- eran mujeres, y para 1912 la Escuela de Enfermeros del municipio porteño decidió restringir el ingreso sólo a éstas. A nivel país, según el censo de 1914, las mujeres representaban el 57,8\% del total en la ocupación, es decir 1.712 sobre 2.963 y, no resulta menor subrayar que, dentro de ese porcentaje, prácticamente el 60\% eran extranjeras (Rodríguez, et. al, 2018, p. 83).
} 
"aprendían las líneas generales de los tratamientos habituales de las enfermedades"33 y acababan por atender todas las especialidades. La responsabilidad directa de esta "plaga" la tendrían sus colegas médicos, diría Licurzi, ya que a "partir de la pereza o negligencia delegan en los enfermeros algunas funciones propias de ellos (...)"34. De manera convergente, la recurrencia a este tipo de empíricos sería la consecuencia de una mayor y mejor comunicación entre "especialista" y "paciente"; en efecto, "para el vulgo son una especie de traducción del médico para que puedan entenderlo"35. Estas apreciaciones peyorativas, sin lugar a dudas, se encontrarían cimentadas en la casi nula profesionalización de los enfermeros radicados en Córdoba en las primeras décadas del siglo XX. En términos numéricos, el censo nacional de 1914 sólo arroja un total de 154 enfermeros en la provincia. En este punto, no debemos soslayar el hecho de que "antes de que aparecieran los espacios de entrenamiento formal, estas actividades especializadas de cuidado de la salud fueron protagonizadas por religiosos de la Orden de los Betlemitas" (Wainerman \& Binstock, 1992, p. 272), así como por "hermanas de la caridad", cuyo protagonismo en la atención hospitalaria es indiscutible hasta mediados del siglo XX. De acuerdo a la visión del galeno, evidentemente, no serían sólo estos últimos grupos los que se ocuparían de ciertos cuidados de la salud de la población, los enfermeros también estarían a cargo-por fuera de los márgenes legales- de aquella actividad.

Acusaciones similares esgrimía Licurzi en torno a la figura de las parteras, pues "excediendo los límites de su saber y de su misión invaden el campo de la medicina" 36 . Ahora bien, el autor se detenía y ponderaba aquí dos escenarios y realidades: la de la campaña, donde "es natural que cualquier mujer atienda partos", y la de la ciudad. En este último enclave, le resultaba penoso que, habiendo "regidos servicios hospitalarios y maternidades, y donde las escuelas de obstetricia vuelcan todos los años un gran número de comadronas diplomadas" ${ }^{37}$, estas prácticas no cesasen, sobre todo en el ámbito hogareño y extrahogareño. Recordemos que la primera escuela ligada a esta rama particular del arte de curar fue la de Buenos Aires, creada en 1875 (Di Liscia, 2005, p. 109) y la segunda del país tuvo asiento en la Universidad de Córdoba en 1884 (Garzón Maceda, 1917). De acuerdo a la denuncia de Licurzi, entonces, podemos conjeturar que, si bien se produjo efectivamente un proceso de jerarquización de los saberes en este oficio desde las postrimerías del siglo XIX, y si bien en las ciudades "las comadronas diplomadas habrían ido desplazando a las parteras sin diploma"38, este corrimiento habría sido incompleto y parcial.

Los boticarios y farmacéuticos recibieron un tratamiento especial por parte de Licurzi. Si en el caso de los enfermeros no refirió siquiera a la posibilidad de que obtuviesen diplomas en las universidades, y en el de las parteras apenas lo mencionaba,

\footnotetext{
${ }^{33}$ Licurzi, 1937, p. 70.

${ }^{34}$ Licurzi, 1937, p. 70.

${ }^{35}$ Licurzi, 1937, p. 70.

${ }^{36}$ Licurzi, 1937, p. 74.

${ }^{37}$ Lucurzi, 1937, p.74.

${ }^{38}$ Licurzi, 1937, p. 75.
} 
Rivero y Carbonetti. ¿Explotadores de la salud? Un estudio sobre miradas médicas desde Córdoba, Argentina, en...

en el de los pharmacopola circunforaneus fue un tópico por excelencia. Aquel subgénero, el de los boticarios, siempre estaría compuesto por personas que "con o sin título

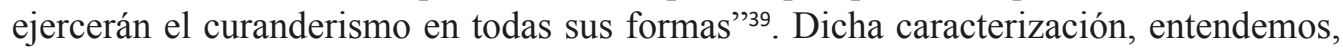
proviene del supuesto proceso de aprendizaje propio de estos creadores de fórmulas magistrales: “(...) del lava frascos al aprendiz; de éste al dependiente; del dependiente al idóneo (...). Sumada a esta falta de instrucción, una suerte de malicia inherente a esta "farmacia práctica" llevaba a los boticarios a no rotular ni colocar membretes en frascos ni envases expedidos, de manera tal que no serían encontrados por las autoridades. Empero, por fuera de las acusaciones del galeno, y como señalan Campins y Pfeiffer (2002), es sabido que estos personajes no ocuparon un lugar menor en el proceso de industrialización farmacológica en Argentina. Los primeros laboratorios nacionales surgieron desde el sector de comerciantes importadores y representantes de firmas extranjeras, o bien desde el saber-hacer de algunos entrepreneurs boticarios a principios del siglo XX.

Los farmacéuticos, por su parte, terminaban extralimitándose cuando "quieren invadir el territorio de la clínica y de la propedéutica" ${ }^{40}$. Resulta interesante, en este punto, reconocer la marcada referencia que realizaba Licurzi en torno a los planes de estudio universitarios diferenciales entre Farmacia y Medicina: en el primero se desarrollaban contenidos relativos a las propiedades de los medicamentos, mientras el segundo implicaba la instrucción en torno a la enfermedad: “(...) es saber relevar signos y síntomas, interpretarlos, traducirlos en equivalentes anatómicos y fisiológicos [...] y deducir las conclusiones diagnósticas certeras" ${ }^{" 41}$. Convergentemente, es de notoria relevancia la explicación acerca de los motivos por los que los farmacéuticos culminaban traspasando los límites de su campo: "la farmacia práctica, es un ambiente que ejerce cierta influencia extraña en personas que en ella trabajan. Cada fórmula que se prepara, o cada específico que se vende suscita, casi subconscientemente, deseos de conocer para qué sirve y para quién sirve. Una coacción psicológica -algo así como el sentimiento de rebelión, de inferioridad ${ }^{42}$, según el concepto adleriano- tortura el espíritu del boticario"43.

Nótese que aquellos entramados ligados a la formación académica distintiva de los médicos y al mal accionar de estos empíricos se encontrarían enraizados en una suerte de necesidad de subordinar a este grupo a la medicina diplomada. Al respecto, González Leandri (1998) recupera las estrategias llevadas a cabo por el cuerpo médico entre mediados y fines del siglo XIX para, precisamente, situar a los farmacéuticos como corporación auxiliar y sometida a su control. Ello se debió al conocido papel protagónico que ocuparon aquellos personajes dentro del área del arte de curar y a que, al igual que los galenos, eran un grupo legalmente privilegiado y su asociación gozaba de cierta influencia. Si bien el autor plantea que este segmento era, para la élite médica,

\footnotetext{
${ }^{39}$ Licurzi, 1937, p. 81.

${ }^{40}$ Licurzi, 1937, p. 79.

41 Licurzi, 1937, p. 79.

${ }^{42}$ La cursiva es nuestra.

${ }^{43}$ Licurzi, 1937, p. 82.
} 
un blanco de disciplinamiento - " "a diferencia de los curanderos y otros irregulares a quienes se intentaba excluir por la índole de su actividad y por el tipo de competencia que planteaban al proyecto médico"- el discurso de Licurzi nos permite registrar que había "muchísimos farmacéuticos aún en las ciudades universitarias, que gozaban fama de curanderos incorregibles" y que había "familias de curanderos con diplomas, es decir farmacéuticos" $" 44$.

La situación de los estudiantes de medicina, quienes también se encontrarían dentro de la congregación de fronterizos, sería (al menos en términos legales), particular: la ley del ejercicio de las artes de curar (art. $2^{\circ}$, año 1891), avalaba en el ejercicio de la medicina a aquellos que estuviesen en los últimos años de la carrea y en enclaves geográficos donde no hubiese médicos diplomados ${ }^{45}$. Ahora bien, Licurzi sostenía que muchos de esos individuos en formación "solían curandear en las mismas ciudades universitarias"46. La misma infracción es identificada en el caso de los alumnos de odontología, pero desde sus primeros años de estudio y a partir de la adquisición de herramientas de trabajo que terminarían por utilizar en lugares poco higiénicos, como las pensiones en las cuales vivían. Esos instrumentales no eran sólo usados para realizar simples extracciones, sino también “(...) hacen puentes, emploman, matan nervios, y se animan a todo lo que han visto hacer a sus profesores"47. Para poder realizar aquellas actividades, estos estudiantes contaban con algún boticario "complaciente" que despachaba recetas. Esta "ayuda" era, en general, un tanto más difícil de obtener para los estudiantes de medicina que, en caso de conseguirla -asevera Licurzi- "seguramente darían más amplitud a sus negocios"48. Si bien las relaciones tensas entre medicina y odontología, identificadas en el escrito del galeno, se definen a partir de la tenencia o falta de título expedido por una alta casa de estudios, aquel vínculo históricamente habría sido complejo, como el trazado con los farmacéuticos. La enseñanza de la odontología en las universidades argentinas a fines del siglo XIX se incluyó entre las denominadas "ramas menores" de la medicina, tal como figura en la ley nacional $n^{\text {o }} 19861$ de creación de la Universidad Nacional del Litoral, que reglamentaba los estudios de la Facultad de Ciencias Médicas, Farmacia y Ramos Menores, entre los que se encontraban la obstetricia y la odontología (Schapira, 2003). A partir de los primeros planes de estudio de las escuelas dentales del país en las primeras décadas del siglo XX, se motorizó un proceso de incorporación de conocimientos ligados a las ciencias básicas, preclínicas y clínicas que despegaba progresivamente a la formación universitaria de las actividades artesanales y mecánicas con que se iniciaron. Esto perseguía, por un lado, lograr deshacerse del rótulo de "rama menor" y a alcanzar un mayor status científico y prestigio social, intentando obtener una autonomía relativa de la medicina, pugnando por espacios de menor subordinación política y académica y, por otro, “deslegitimar

\footnotetext{
${ }^{44}$ Licurzi, 1937, p.81.

45 Esta normativa también incluía a galenos extranjeros no revalidados. Para mayor información véase Stucchi (1916).

${ }^{46}$ Licurzi, 1937, p. 88.

${ }^{47}$ Licurzi, 1937, p. 90.

48 Licurzi, 1937, p. 87.
} 
Rivero y Carbonetti. ¿Explotadores de la salud? Un estudio sobre miradas médicas desde Córdoba, Argentina, en...

prácticas competitivas como las del mecánico dentista, a partir de la incorporación en la formación de grado de amplios conocimientos de prótesis" (Schapira, 2003, p. 965). Sin embargo, no sería sino hasta finales de la década de 1930, precisamente, que la especialidad adquiriría mayor visibilidad en términos profesionales. Posiblemente, esta coyuntura de mayor protagonismo de los odontólogos en la esfera de la salud habría puesto en alerta a la élite médica, de la cual Licurzi formaba parte.

\section{Charlatanes médicos: el caso Andreatti}

"Los diccionarios de la lengua toscana de fines del siglo XVI definían al charlatán como un viajante que trafica ungüentos y otros remedios, saca dientes y también hace exhibiciones en la plaza pública" (Podgorny, 2012, p. 14). Se trataba de sujetos que, en el marco de una dinámica publicitaria tendiente a exhibir sus productos, apelaban a la realización de acrobacias, recitaciones, juegos de mágica, cánticos, etc. Ahora bien, tal y como señala Podgorny (2012), tanto estos individuos engañosos como los médicos itinerantes realizaban viajes para ofertar sus servicios, hecho que en sobradas oportunidades tornó difícil la tarea de distinguir a unos de otros. No obstante, remarca la autora, "ese carácter trashumante sobreviviría como marca real o ficticia de los remedios y vidas de los fraudulentos" (Podgnorny, 2012, p.15).

Al respecto, Licurzi y Bermann identificaron entre este grupo de viajeros, ofertantes de productos dudosos y extremadamente comerciantes, a ciertas personalidades de la medicina diplomada. Esta tendencia fue aprehendida como "curanderismo médico" o "charlatanismo". La desagregación de la información que provee el discurso de Licurzi permite constatar que su preocupación respecto de este tipo de prácticas radicaba en la pérdida o carencia de moral profesional. Si bien reconocía que "el comercialismo médico en verdad existió siempre [...] antes el médico aparentaba no ocuparse personalmente de su propaganda exagerada o charlatanesca" 4 . Ofuscado por esta "nueva fase del proceso, en que el médico asume [...] la dirección de su réclame", el galeno advertía —a partir de los "(...) anuncios que colman las páginas de los periódicos, espacios donde se libran las batallas por conseguir clientes ${ }^{50}$ - que la suya era una época de "miseria moral". De acuerdo a su perspectiva, aquel período sería aprovechado por "(...) ciertas organizaciones tituladas de mutualistas y cooperativistas, obligando a sus médicos a ver en dos o tres horas cincuenta o sesenta enfermos reclutados con engañosas promesas asistenciales" $"$.

De las declaraciones que venimos reseñando se desprenden, al menos, dos cuestiones centrales: por un lado, la caducidad de la imagen santificada del médico. Recordemos que, como lo expresa Di Liscia (2002), durante el siglo XIX se intentó construir una figura idealizada sobre los galenos en general; se trataba de personas íntegras, incorruptibles, preocupadas por el bienestar de la humanidad doliente. Ulteriormente, y conforme al avance del proceso de medicalización en Argentina, muchos

\footnotetext{
${ }^{49}$ Licurzi, 1937, p. 96.

50 Licurzi, 1937, p. 98.

${ }^{51}$ Licurzi, 1937, p.98.
} 
miembros de esta élite se resistieron a encajar su profesión bajo el signo humanitario. Si la medicina era una profesión, en la cual se habían invertido años de estudio y de trabajo, el médico debía poder vivir de ella, es decir, debía ser una labor rentable en la cual se develaran los conocimientos técnicos y los pacientes pagaran por su curación. Si bien, como marcáramos previamente, Licurzi no desconocía esta vertiente mercantil de la actividad, su reclamo giraba en torno a los "excesos" y al aprovechamiento de determinadas tendencias epidemiológicas para el beneficio propio, que se alejaban de una postura "ética". En efecto, el galeno referenciaba la existencia de enfermedades sociales que aquejaban a la población: tuberculosis, sífilis e impotencia; las últimas dos -de acuerdo a su visión- predominaban en los anuncios, fundamentalmente porque “(...) preocupaban en razón a la cultura de los hombres" "52. Estos avisos -como lo ilustra la figura 4- darían cuenta de las iniciativas inescrupulosas y "falta de pudor profesional".

Figura 4

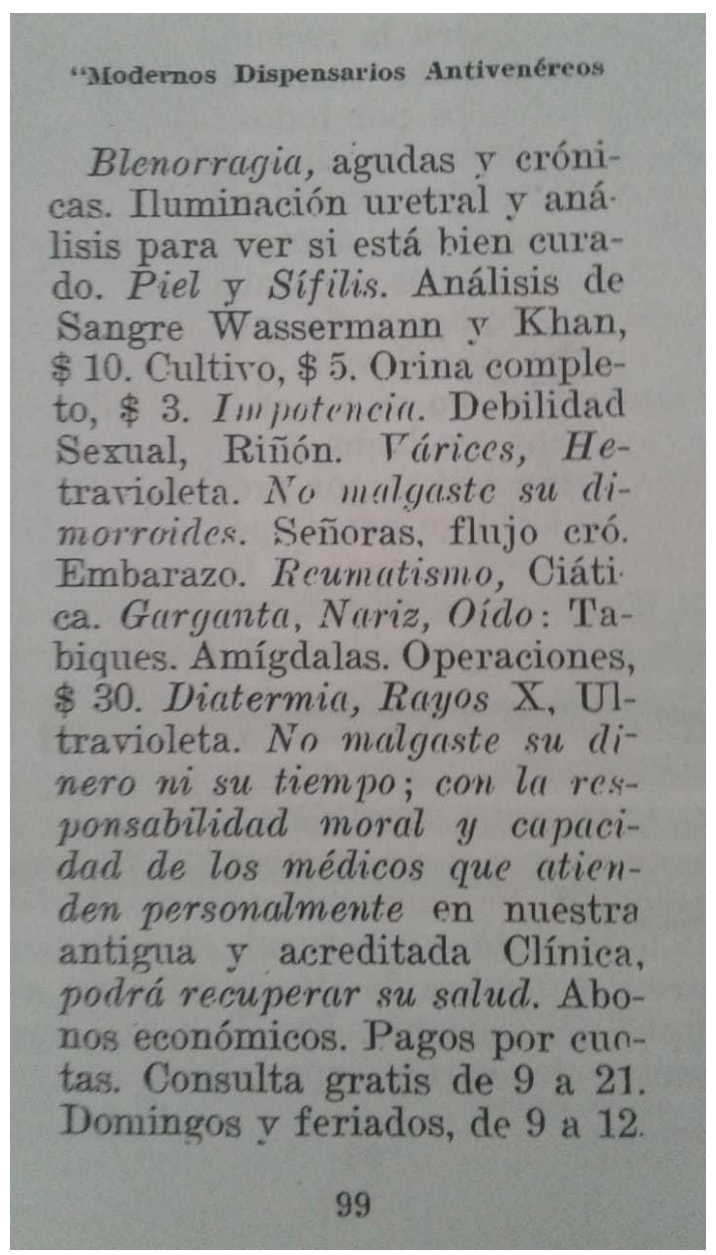

${ }^{52}$ Licurzi, 1937, p. 98. 
Rivero y Carbonetti. ¿Explotadores de la salud? Un estudio sobre miradas médicas desde Córdoba, Argentina, en...

En segundo lugar, las reflexiones de Licurzi nos conducen a interrogarnos por la configuración de la salud pública y privada en Córdoba durante la década de 1930. Al respecto, Ortiz Bergia (2012) señala que, desde la segunda mitad del decenio en adelante, la atención de las condiciones sanitarias de la población alcanzó un lugar más preponderante que en las décadas previas, aunque todavía se mantuvo subordinada a otras problemáticas económicas y políticas provinciales. En término generales, las transformaciones del sistema de salud se ligaron a la aparición de un mayor número de prestadores privados, a través de la instalación de empresas médicas y de los primeros hospitales pertenecientes a mutualidades obreras ${ }^{53}$. Junto con ellos, otros dispositivos sanitarios aumentaron sus prestaciones en esa época. De manera específica, cabe destacar que, a partir de 1932, comenzaron a erigirse dispensarios seccionales en distintos puntos de la ciudad que permitieron redistribuir los servicios del centro de la urbe hacia los barrios suburbanos. Convergentemente, en ese período, tanto en la ciudad como en la provincia de Córdoba, el Estado nacional también articuló un sistema de consulta médica más amplio del que había desarrollado en las décadas previas. Este hecho que constituyó un indicio de la mayor participación de las reparticiones nacionales en las prestaciones de salud y de sus intentos por distribuirlas, en forma más efectiva, en el extenso territorio argentino. Por último, por esos años, el Estado provincial también adquirió predominio en el mantenimiento de los servicios de consulta médica. Este proceso se inició durante la primera mitad de la década de 1930, momento en que se crearon, en el interior cordobés, los llamados dispensarios de profilaxis general y primeros auxilios (Ortiz Bergia, 2015, pp. 564- 566). Este avance progresivo de la intervención estatal en el sistema de salud, que como hemos marcado generaría una mayor oferta para usuarios diferenciales, no se tradujese, tal vez, como señalaba Licurzi, en un mejoramiento de las condiciones de trabajo y de vida de los galenos.

Retomando las enumeradas dolencias sociales, no podemos soslayar el aporte de Gregorio Bermann en torno al charlatanismo ligado específicamente a la tuberculosis. Su célebre trabajo titulado "La explotación de los tuberculosos" (1941) abordaba lo que, junto con Dechambre, denominaba "charlatanismo de gabinete", a partir del examen de ciertos casos de personalidades que habrían propuesto tratamientos y curas milagrosas para la conocida "peste blanca". En el presente estudio nos enfocaremos en el del Dr. J.B Andreatti, quien habría logrado perturbar el ambiente médico argentino por muchos años, engañando a destacadas figuras y recetando sus productos, e incluso "esgrimiendo [...] ofensivos ataques contra autoridades consagradas [...] del medio" ${ }^{54}$. Al respecto, Licurzi también remarcaba que con su "pretendida vacuna contra la tuberculosis, engañó al público de todo el país y comprometió hasta nombres respetados y prestigiosos de la medicina argentina" ${ }^{\prime 5}$. Bermann reconocía, sobre la trayectoria de Andreatti, que se

\footnotetext{
${ }^{53}$ Claro que, no debemos perder de vista que estos nuevos establecimientos y su dispersión en el territorio provincial implicaron la construcción paulatina de una oferta orientada a satisfacer la demanda de los sectores con mayor poder adquisitivo, delimitando también una clientela para los servicios hospitalarios públicos, centrada en los sectores más empobrecidos de la sociedad (Ortiz Bergia, 2015).

${ }^{54}$ Bermann, 1941, p. 14.

${ }^{55}$ Licurzi, 1937, p.106.
} 
había diplomado en la Facultad de Medicina de Viena, pero ignoraba si había revalidado su título. Presentándose en Argentina, en el Congreso Médico Nacional Antituberculoso celebrado en la ciudad Rosario ${ }^{56}$ en 1919 (ingreso que se le negaría en la edición del año 1927), y publicando trabajos en la Revista del Círculo Médico de aquella urbe, el vienés expondría sus conclusiones acerca del diagnóstico y terapéuticas de la dolencia. Al respecto, Bermann (1941) señalaba que:

(...) mientras trata las formas con hipotermia o con temperatura aproximadamente normal, con una tuberculina $[\ldots]$ que suministra por gotas y por vía gástrica, en las formas mixtas agrega una vacuna polivalente que dice haber descubierto y lleva su nombre. Con estas simplísimas ideas insiste repetidamente en haber hecho una revolución de inapreciables consecuencias para la lucha contra la peste blanca, no sólo porque cura a los tuberculosos, sino también porque con otras terapéuticas resulta una pérdida considerable para la economía y ni lejanamente se obtienen éxitos por el logrados (p. 17).

De manera convergente, el psiquiatra argentino observaba que Andreatti colocaba un marcado énfasis en sus argumentaciones sobre la necesidad de llevar a cabo un diagnóstico precoz, pues este permitiría el establecimiento de un "(...) tratamiento rápido y radical en muy escaso tiempo" 57 , al tiempo que, aparentemente, dilapidaba a los especialistas que no acogían sus principios y tratamientos. No obstante, Bermann indicaba que la afirmación categórica de Andreatti acerca de que "su método es radical para el tratamiento de la tuberculosis en un 95\% de los casos" no había tenido demostración ni en Argentina ni en ninguna parte del mundo. En efecto, sus experimentaciones en nuestro país nunca llegarían a término, ya que "siempre debió interrumpirlo, porque según afirma, encontró la oposición de los que temían ver coronado su tratamiento por un éxito completo..." ${ }^{\text {88 }}$. En el caso de Viena, aparentemente, Andreatti sostenía que no había podido concluir con sus investigaciones clínicas, pues se le había agotado el stock de preparados, mientras simultáneamente se le presentaban necesidades urgentes de viajar. Estas interrupciones intempestivas, sin embargo, terminaron por ser unas de las bases más elementales de su propaganda y, al mismo tiempo, la muestra acabada de su actividad práctica.

Ahora bien, nuestro interés en este personaje particular se encuentra anclado no sólo en la descripción y críticas que Bermann realizaba acerca de sus tratamientos (contrapuestos, mayoritariamente, a los avalados por la ciencia médica de época), y a sus maneras de promocionarlos (en folletos, diarios y revistas de circulación masiva). De hecho, estos aspectos discursivos no difieren de las apreciaciones de Licurzi acerca

\footnotetext{
${ }^{56}$ Para ese entonces, Andreatti ya habría “(...) peregrinado por muchas partes [...] Ya había actuado en algunos hospitales europeos, en su país, en Brasil, Paraguay y aún antes en la República. (Bermann, 1941, p. 16)

${ }^{57}$ Bermann, 1941, p. 19.

${ }^{58}$ Bermann, 1941, p. 21.
} 
Rivero y Carbonetti. ¿Explotadores de la salud? Un estudio sobre miradas médicas desde Córdoba, Argentina, en...

del charlatanismo. Concretamente, la variante que se plantea en el caso Andreatti es que Bermann terminaba por realizar un diagnóstico sobre él. Desde la perspectiva del psiquiatra, "por grande que hubiera sido su codicia y su espíritu de falsedad, no hubiera llegado a situaciones tan extremas y tan chocantes, de haber sido una persona normal" 59 . La anomalía de Andreatti se encontraba cimentada, verosímilmente, en los rasgos de una personalidad psicopática. Entre ellos, en primer lugar, es dable destacar, indicaba Bermann "(...) su egolatría, su hipertrófica vanidad, el orgullo verdaderamente paranoico con que se exhibe como salvador de la especie. Imbricada a esta cuestión, son aprehensibles también sus ideas prevalentes: "se exhibe como el descubridor [...] del tratamiento específico de la tuberculosis [...] Reivindica para sí el patrocinio de toda idea racional enunciada posteriormente a sus publicaciones, pero que ya eran del dominio común mucho antes"60. El tercer rasgo psicopático, identificado por Bermann, era la agresividad del vienés. Aparentemente, en un escenario hostil, en el cual se sentía perseguido por miembros de la élite médica argentina, sus repuestas — públicas, expuestas en congresos y periódicos - eran ofensivas y denigrantes para aquellos galenos. Directamente asociado a este rasgo, se encontraría el cuarto: la hipomanía, definida como una condición afectiva caracterizada por un ánimo persistentemente expansivo, hiperactivo y/o irritable, como también por pensamientos y comportamientos consecuentes a dicho ánimo (Rosenfeld, 1964). Este estado se manifestaba en Andreatti a partir de su actividad: “( ...) se lanza en diferentes empresas, pasa de un país al otro, reclama sus derechos ante las diferentes sociedades científicas y académicas, interviene en congresos...cuando lo dejan, dirige cartas públicas, envía carteles de desafío"61. Además de los mencionados elementos distintivos de la personalidad de Andreatti, el psiquiatra señalaba que colindaba con la paranoia; "con persistencia, con ardor, busca razones o apariencias de razones, para confirmar o invalidar las opiniones contrarias o favorables a sus intereses o a sus sentimientos"62.

De manera evidente, estos rasgos patológicos no serían los de un alienado o un delirante. En este sentido, Bermann afirmaba -citando a Jean Paulhan ${ }^{63}$ - que existían espíritus falsos y verdaderos, y que Andreatti se encontraría cabalmente entre los primeros. Esta particularidad no lo excluía de ciertas cualidades intelectuales: "Serieux y Capgras reconocen que aún entre los afectados del delirio de persecución los hay que revelan actitudes nobles: imaginación brillante, memoria segura, razonamientos hábiles" ${ }^{64}$. Siguiendo a estos dos autores, Bermann terminaba por ubicar a Andreatti en un cuadro clínico: el del delirio por reivindicación, signado por "ideas obsedantes y exaltación maníaca" ligadas, fundamentalmente, a sus ansias apostólicas, de servir y salvar a la humanidad ${ }^{65}$. Ahora bien, a partir del soporte teórico consultado y las

\footnotetext{
${ }^{59}$ Bermann, 1941, p.31.

${ }^{60}$ Bermann, 1941, pp.32-33.

${ }^{61}$ Bermann, 1941, p. 33.

${ }^{62}$ Bermann, 1941, p. 35.

${ }^{63}$ Famoso escritor francés, ícono del siglo XX.

${ }^{64}$ Bermann 1941, p.35.

${ }^{65}$ Bermann, 1941, p. 36.
} 
conclusiones diagnósticas a las que arribaba, el psiquiatra aseveraba que "Andreatti debe responder por entero de sus actos, no sólo porque no se trata de un alienado sino también por su peligrosidad social [...] La verdad es que se trata de un charlatán injertado en un temperamento reinvindicador. Hay que confesar que este psicópata supo aprovechar muy bien para su comercio las condiciones morbosas de su mente"66.

Sin lugar a dudas, la estrategia del psiquiatra distaba de la de muchos de sus colegas. En pos de defender su profesión, de exponer los peligros de la naturalización y extensión de la "superchería", Bermann apelaba a las herramientas que le proveía su labor y campo de conocimiento para desmitificar el accionar de Andreatti. Al cuestionarse si "los impostores [como él] saben efectivamente si lo son" que, al menos por períodos, no lo ignoraban. Esta suerte de claridad intermitente es la que, de acuerdo a su visión, establecía que no debían ser eximidos de su responsabilidad en cuanto a las conductas impertinentes que llevaban a cabo.

\section{Consideraciones finales}

Las prácticas empíricas de curar han ingresado reciente y tímidamente en la historiografía local. Son exiguos, aún, los estudios que colocan en el centro de la escena analítica a curanderos, charlatanes y otros integrantes de un subgrupo que se encontrarían por fuera de los márgenes de la biomedicina y/o de la legalidad. Intentando nutrir esta corriente, aún joven dentro del área de la nueva historia socio-cultural de la enfermedad, en el presente trabajo nos propusimos rescatar las voces de médicos profundamente ligados al campo "psi" y de la criminología en la provincia de Córdoba, que trascendieron las fronteras locales logrando ocupar espacios de poder incluso a escala nacional. De manera específica, entendemos que los discursos de Gregorio Bermann y Ariosto Licurzi -plasmados en sus obras- sobre el curanderismo y el charlatanismo mostraron un inquietante y continuo malestar de quienes conformaban el ámbito de la salud pública y el de la formación universitaria. Asimismo, el examen de esos entramados discursivos develó que el "enemigo" no se encontraba sólo en las filas de quienes no poseían título universitario, sino que también fue susceptible de ser hallado dentro de los límites de la ciencia médica certificada. En efecto, el caso del Dr. Andreatti mostraría que su origen extranjero, sus diagnósticos y tratamientos -entre otros elementos- terminarían por colocarlo dentro del grupo de charlatanes. La reticencia de la ciencia médica local a aceptarlo como colega no acabaría en la denuncia o protesta respecto a su accionar en Argentina. Bermann redoblaría la apuesta y terminaría por establecer que se trataba de un sujeto con rasgos de personalidad psicopática.

Finalmente, consideramos que, desde la óptica de los galenos, el abordaje de la diseminación de este "mal social", cuyos responsables, según los autores, serían los propios médicos, las autoridades gubernamentales y policiales, entre otros, implicaba, necesariamente, cierta discriminación y clasificación, en congruencia con una marcada lógica positivista. Pero antes de llevar a cabo tamaña empresa, era menester remontarse

\footnotetext{
${ }^{66}$ Bermann, 1941, p. 36.

${ }^{67}$ Bermann, 1941, p. 38.
} 
Rivero y Carbonetti. ¿Explotadores de la salud? Un estudio sobre miradas médicas desde Córdoba, Argentina, en...

a los orígenes de estas prácticas empíricas. A lo largo de nuestro estudio hemos indagado en aquella taxonomía, definida a partir de tres grandes grupos: brujos, espiritistas, farmacéuticos, estudiantes de medicina y odontología, hasta médicos considerados inescrupulosos, entre otros; y en el estadio inicial de las prácticas del curar ajenas a la medicina alopática, sin perder de vista que sus descriptores eran fervientes defensores del gremio médico diplomado. Dicho conjunto ilustrado y su capacidad de asociación representaban, efectivamente, una pieza clave del rompecabezas de la medicalización. Empero, la existencia y circulación masiva de los "curadores" abordados da cuenta de que aquel proceso no sería lineal ni tendría límites concretos, como tampoco una fecha o período de concreción absoluta.

\section{Fuentes}

Bermann, G. (1941). La explotación de los tuberculosos. Buenos Aires: Editorial Claridad. Universidad Nacional de Córdoba, Córdoba, Centro de Estudios Avanzados (CEA), Archivo Gregorio Bermann.

Licurzi, A. (1937). Los explotadores de la salud. Curanderos y charlatanes. Estudio médico legal y ccriminológico. Córdoba: Pereyra. Universidad Nacional de Córdoba, Córdoba, Hemeroteca de la Facultad de Ciencias Médicas.

Manuscrito Gregorio Bermann. Universidad Nacional de Córdoba, Córdoba, Centro de Estudios Avanzados (CEA), Archivo Gregorio Bermann.

\section{Referencias bibliográficas}

Acosta Witter, N. (2001). Dizem que foi feitiço: As práticas da cura no sul do Brasil (1845-1880). Porto Alegre: EDIPUCRS.

Acosta Witter, N. (2005). "Curar como arte e ofício: contribuições para um debate historiográfico sobre saúde, doença e cura". Tempo, Rio de Janeiro, (19), 13-25.

Allevi, J. I., Carbonetti, A., y Sedrán, P. M. (2018). "Médicos, administradores y curanderos. Tensiones y conflictos al interior del arte de curar diplomado en la provincia de Santa Fe, Argentina (1861-1902)". Anuario de Estudios Americanos, 75(1), 295-322.

Amodio, E. (1997). "Curanderos y médicos ilustrados. La creación del Protomedicato en Venezuela a finales del siglo XVIII". Asclepio, 49(1), 95-129.

Ansaldi, W. (1992). "Una modernización provinciana: Córdoba, 1880-1914”. Estudios, $8,51-80$.

Arana Cañedo J. (2001). "El panteísmo y sus formas". Revista de filosofia, 57, 5-18.

Armus, D. (2002). "La enfermedad en la historiografía de América Latina moderna". Asclepio, 54(2), 41-60.

Armus, D. (2007). La ciudad impura. Salud, tuberculosis y cultura en Buenos Aires, 1870-1950. Buenos Aires: Edhasa.

Armus, D. (2016). "Medicina casera, remedios y curanderos en los inicios de la medicalización de la ciudad moderna. Buenos Aires, 1870-1940". Tempos Históricos, 20(1), 47-80. 
Belmartino, S. (2005). La atención médica argentina en el siglo XX. Instituciones y procesos. Buenos Aires: Siglo XXI.

Bianchi, S. (2012). Historia de las religiones en la Argentina: las minorías religiosas. Buenos Aires: Sudamericana.

Bubello, J. P. (2010). Historia del esoterismo en la Argentina. Prácticas, representaciones y persecuciones de curanderos, espiritistas, astrólogos y otros esoteristas. Buenos Aires: Biblos.

Carbonetti, A. (2003). "La mortalidad infantil en la ciudad de Córdoba. entre principios y mediados del siglo XX”. Ponencia. VI Jornadas Argentinas de Estudios de Población, Buenos Aires, Asociación de Estudios de Población de la Argentina. Ms.

Carbonetti, A. (2005). "La conformación del sistema sanitario de la Argentina. El caso de la Provincia de Córdoba, 1880-1926". Dynamis: Acta Hispanica ad Medicinae Scientiarumque Historiam Illustrandam, 25, 87-116.

Cárcamo, H. (2005). "Hermenéutica y Análisis Cualitativo”. Cinta moebio, 23, 204-216.

Dahhur, A. (2013). "Ataques a curanderos. La medicina y su lucha por el control social de la población en los primeros años del siglo XX”. Ponencia. XIV Jornadas Interescuelas/Departamentos de Historia. Mendoza. Ms.

Dahhur, A. (2018). "Las causas del curanderismo según la prensa en Tandil y en Buenos Aires a principios del siglo XX”. Question, 1(59), 063.

Dahhur, A. (2012) “Curanderos y médicos ¿antagónicos o complementarios? Tandil a fines del siglo XIX”. Ponencia. Jornadas de Iniciación en la Investigación Interdisciplinaria en Ciencias Sociales. Bernal. Ms.

Di Liscia, M. S. (2002). Saberes, terapias y prácticas médicas en Argentina (17501910). Madrid: CSIC.

Farberman, J. (2005). Las salamancas de Lorenza: magia, hechicería y curanderismo en el Tucumán colonial. Buenos Aires: Siglo Veintiuno Editores.

Fernández, M. E y Parolo, M.L. (2008). “Controles, manifestaciones y límites del arte de curar en Tucumán durante el siglo XIX”. En A. Carbonetti y R González Leandri (eds.), Historias de salud y enfermedad en América Latina. Siglos XIX y XX. (95-117). Córdoba: CEA-CONICET, Universidad Nacional de Córdoba.

Ferrari, F. (2011). "Modos de representar e intervenir la patología mental en Córdoba (192645). El caso de Ariosto Licurzi y la degeneración". Representaciones (7)1, 25-42.

Figueiredo, B. (2002). A Arte de Curar: cirurgiões, médicos, boticários e curandeiro no século XIX em Minas Gerais. Rio de Janeiro: Vicio da Leitura.

Fleitas, M. (2014). Médicos y curanderos de San Salvador de Jujuy a comienzos del siglo XX". Tesis de doctorado en Historia, Universidad de Jujuy. Ms.

Garzón Maceda, F. (1917). La medicina en Córdoba. Apuntes para su Historia. Buenos Aires: Rodríguez Giles.

Gastó, C. y Navarro, V. (2006). Introducción a la psicopatología ya la psiquiatría. España: Elsevier Masson.

González Leandri, R. (1997). “Académicos, doctores y aspirantes. La profesión médica y la reforma universitaria: Buenos Aires 1871-1876”. Entrepasados, Revista de Historia, 12, 31-54. 
Rivero y Carbonetti. ¿Explotadores de la salud? Un estudio sobre miradas médicas desde Córdoba, Argentina, en...

González Leandri, R. (1998). “Autonomía y subordinación: los farmacéuticos diplomados y la constitución de un campo médico en Buenos Aires (18521880)". Llull: Revista de la Sociedad Española de Historia de las Ciencias y de las Técnicas, (21) 40, 63-88.

González Leandri, R. (1999). Curar, persuadir, gobernar: la construcción histórica de la profesión médica en Buenos Aires, 1852-1886. Madrid: Editorial CSIC.

Huertas, R. (2012). Historia cultural de la psiquiatría. (Re)pensar la locura. España: Catarata.

Márquez Valderrama, J., García, V., y Delvalle, P. (2012). "La profesión médica y el charlatanismo en Colombia en el cambio del siglo XIX al XX”. Quipu, 14(3), 331-362.

Martin, A. L. (2015). Mujeres y enfermería: una asociación temprana y estable (18861940). En C. Biernat, J. M. Cerdá \& K. Ramacciotti (dirs.), La salud pública y la enfermería en la Argentina (pp. 257-274). Bernal, Argentina: Universidad Nacional de Quilmes.

Módena, M.E. (2002). Combinar recursos curativos: un pueblo mexicano en las últimas décadas del siglo XX. En: D. Armus (comp.), Entre médicos y curanderos: cultura, historia y enfermedad en la América Latina moderna (pp. 331-370). Buenos Aires: Grupo Editorial Norma.

Moreyra, B. (2009). Cuestión social y políticas sociales en la Argentina: la modernidad periférica, Córdoba, 1900-1930. Bernal: Universidad Nacional de Quilmes.

Moreyra, B. I., y Domínguez, I. M. (2012). "La salud y enfermedad desde una perspectiva sociocultural en la primera mitad del siglo XX". Revista de la Facultad de Ciencias Médicas, 69 (3), 165-173.

Moreyra, C. E. (2011). "Pensar los objetos. Problemas y fuentes para el estudio de la cultura material en la época colonial”. Anuario de Arqueología, 3, 121-141.

Mossi, M. (1872). Discursos filosóficos sobre el magnetismo y espiritismo. Buenos Aires: Imprenta de la Sociedad Anónima.

Ortiz Bergia, M. J. (2015). "La temprana descentralización de los servicios de salud en la Argentina: la construcción del sistema sanitario en Córdoba, 1930-1955". História, Ciências, Saúde-Manguinhos, 22 (2), 559-575.

Ortiz Bergia, M. J. (2012). "La salud pública en transformación. La estructuración de políticas sanitarias en Córdoba-Argentina, 1930-1943”. Asclepio, 64 (1), 121-146.

Palmer, S. (2002). "La voluntad radiante del profesor Carbell: medicina popular y populismo médico en Costa Rica en el decenio de 1930”. En: D. Armus (comp.), Entre médicos y curanderos: cultura, historia y enfermedad en la América Latina moderna (pp. 259-292). Buenos Aires: Grupo Editorial Norma.

Pfeiffer, A., y Campins, M. (2002). Cien años de Industria Farmacéutica en la Argentina (1900-2000). Buenos Aires: UBA.

Pimenta Salgado, T. (1997). Artes de curar: um estudo a partir dos documentos da Fisicatura-mor no Brasil do começo do século XIX. Tesis de maestría em Historia, Universidad de Campinas. Ms.

Pimenta Salgado, T. (1998). "Barbeiros- sangradores e curandeiros no Brasil (180828)". História, Ciências, Saúde-Manguinhos, (5) 2, 349-374. 
Pimenta Salgado, T. (2003). O exercício das Artes de Curar no Rio de Janeiro (18281855). Tesis de doctorado en Historia, Universidad de Campinas. Ms.

Podgorny, I. (2012). Charlatanes: crónicas de remedios incurables. Buenos Aires: Eterna Cadencia.

Rivero, D., y Vanadía, L. (2018). "En los márgenes de la biomedicina: perspectivas en torno a la práctica ilegal de la medicina en Córdoba y Buenos Aires, 1920-1930". Trashumante: Revista Americana de Historia Social, (11), 98-121.

Rivero, M. D., Carbonetti, A., y Rodríguez, M. L. (2017). "Alternativas al saber diplomado en la escena pública: una aproximación al curanderismo a partir de la prensa escrita de las ciudades de Córdoba y de Buenos Aires, Argentina en la década de 1920". Revista Historia y Sociedad, (33), 19-43.

Rodríguez, M. L., Aizenberg, L., y Carbonetti, A. (2018). “Construcciones de género sobre las mujeres curanderas: miradas desde la medicina y el periodismo en la ciudad de Córdoba, Argentina, durante las décadas de 1920 y 1930". Trashumante. Revista Americana de Historia Social, (12), 120-141.

Rodríguez, M. L., Carbonetti, A., Rivero, M. D., y Fantin, M. A. (2018). “Ocupaciones de la salud en el territorio argentino: perspectivas a partir de los censos nacionales de 1869, 1895 y 1914". Población \& Sociedad, 25 (1), 75-101.

Rosenfeld, H. (1964). "Una investigación de la teoría psicoanalítica de la manía y de la hipomanía”. Revista de psicoanálisis, 21 (4), 293-357.

Larson, M. S. (1979). The rise of professionalism: A sociological analysis. United States: Univ of California Press.

Schapira, M. V. (2003). "La odontología en Argentina: historia de una profesión subordinada". História, Ciências, Saúde-Manguinhos, 10 (3), 955-77.

Souza Soares, M de. (1999). A doença e a cura-saberes médicos e cultura popular na Corte Imperial”. Tesis de maestría en Historia, Universidad Federal Fluminense. Ms.

Souza Soares, M de. (2001). "Médicos e mezinheiros na Corte Imperial: uma herança colonial". História, Ciências, Saúde-Manguinhos. 8 (2), 407-438.

Sowell, D. (2002). "Andanzas de un curandero en Colombia: Miguel Perdomo Neira y "la lucha entre el buen sentido y la ignorancia ciega"'. En: D. Armus (comp.), Entre médicos y curanderos: cultura, historia y enfermedad en la América Latina moderna (pp. 71-3104). Buenos Aires: Grupo Editorial Norma.

Suriano. J. (2000). La cuestión social en la Argentina. 1870-1943. Buenos Aires: Editorial La Colmena.

Tunnermann, C. (2008). Noventa años de la Reforma Universitaria de Córdoba. Buenos Aires: CLACSO.

Vallejo, M. (2015). "Voces del más acá: espiritistas y médicos en la cultura científica de Buenos Aires (1880-1900)". Boletín del Instituto de Psicología Paranormal, (10) $1,20-30$.

Vallejo, M. (2016). "Espiritismo y psiquiatría en Buenos Aires a fines del siglo XIX. Un análisis de la obra de Wilfrido Rodríguez de la Torre (1889)". Anuario de Investigaciones, 23 (2), 305-313. 
Rivero y Carbonetti. ¿Explotadores de la salud? Un estudio sobre miradas médicas desde Córdoba, Argentina, en...

Vallejo, M. (2018). "El Instituto Psicológico Argentino (1892). Teosofía, hipnosis y charlatanería en los orígenes de una iniciativa olvidada". Asclepio, 70 (1), 217.

Wainerman, C. y Binstock, G. (1992). "El nacimiento de una ocupación femenina: la enfermería en Buenos Aires". Desarrollo económico, 271-284. 